\title{
Influence of DSC thermal lag on evaluation of crystallization kinetics
}

Roman Svoboda*1, Luis Pérez Maqueda², Veronika Podzemná, Ondřej Svoboda

1 Department of Physical Chemistry, University of Pardubice, Studentska 573, 53210 Pardubice, Czech Republic

${ }^{2}$ Instituto de Ciencias de Materiales (C.S.I.C), Universidad de Sevilla, Apdo. 1115, 41071 Seville, Spain

\section{Abstract}

Influence of added thermal resistance on crystallization kinetics measured by differential scanning calorimetry (DSC) was studied for the $\mathrm{Se}_{70} \mathrm{Te}_{30}$ glass. The increase of thermal resistance was realized by adding polytetrafluorethylene discs of different thicknesses (up to $0.5 \mathrm{~mm}$ ) in-between the DSC platform and the pan with sample. Increase of the thermal resistance led to significant changes of model-free kinetics - apparent activation energy $\mathrm{E}$ of the crystallization process decreased (by more than $20 \%$ ) due to the DSC data being progressively shifted to higher temperatures with increasing heating rate. This distortive effect increased in the following order depending on the type of evaluation: peak-maximum-based method $<$ integral isoconversional method $<$ differential isoconversional method. The modelbased kinetics was, on the other hand, changed only slightly; the DSC peaks retained their asymmetry and the choice of the appropriate model was not influenced by the added thermal resistance. Apparent enthalpy of the crystallization process decreased significantly (by more than $30 \%$ ). Kinetic predictions were significantly affected when extrapolated by $>20^{\circ} \mathrm{C}$ due to the deviation in E values; the errors arising from the added thermal resistance were however still smaller than those associated with the prediction being potentially based on the data obtained at high heating rate (instead of low ones that are closer to both isothermal and low temperature kinetic behavior). The temperature shift caused by added thermal lag was modeled for the low-to-moderate heating rates.

Keywords: thermal lag, kinetic analysis, DSC, JMA model, chalcogenide glass

\footnotetext{
"Corresponding author: Tel.: +420 466037346 E-mail address: roman.svoboda@upce.cz
} 


\section{Introduction}

With the relatively recent progressively accelerating development of thermo-analytical instrumentation, a similar advancement can be noted also for the theory of kinetic analysis, with the accent being shifted from the single-process analysis [1,2] to complex kinetic evaluations [3-10]. The increased precision and reliability of the thermo-analytical instruments also allows studying various kinetics-influencing effects possibly occurring during the materials processing and storage (e.g. aging [11] or subtle degradation [12] effects), and accounting for the data-distortive effects as a consequence of either simplified kinetic evaluations themselves (e.g. baseline subtraction $[13,14]$ or replacement of the complex thermal history by a simple one [15]) or instrumental artifacts. With regard to the latter, a relatively low attention is paid to the question of the system thermal lag and its influence on the kinetic evaluations in the solid-state systems. Whereas the instrumental lag is being minimized by the companies producing the thermo-analytical equipment, the inherent lag associated with the measured materials and the interfaces present in the system persists. [16] Pronounced manifestation of thermal gradients can be usually avoided by following the methodological recommendations for kinetic thermo-analytical measurements and evaluations $[1,2,17]$ in case of the standard modern differential scanning calorimeters DSCs or thermogravimetric analyzers TGAs but the problem is still open for the large-mass instrumental techniques (e.g. differential thermal analysis DTA [18], dilatometry [19] ...) or for the cutting edge research produced using the ultra-fast scanning calorimetry FSC [20]. Similar issue can be also encountered when comparing measurements performed in e.g. alumina and aluminium DSC pans without full heating-rate-based calibration.

In the present paper the influence of artificially introduced thermal lag on the thermokinetic DSC measurements and their evaluations will be studied. The added thermal resistance will be realized using PTFE (polytetrafluorethylene) discs; crystallization of the 
finely milled $\mathrm{Se}_{70} \mathrm{Te}_{30}$ chalcogenide glass will be used as a model process due to its very good reproducibility and single-process nature [21]. Advanced methodological approaches will be utilized to analyze the consequences of thermal lag for the kinetic predictions; the origin of the thermal lag will be discussed.

\section{Experimental}

The $\mathrm{Se}_{70} \mathrm{Te}_{30}$ glass was prepared by the standard melt-quench method, by introducing the adequate amounts of pure elements (Sigma-Aldrich, $5 \mathrm{~N}$ purity) into the evacuated fused silica ampoules and quenching them (after annealing at $650{ }^{\circ} \mathrm{C}$ for $24 \mathrm{~h}$ in a rocking furnace) in water. The as-prepared chalcogenide glassy ingot was ground, milled and sieved via defined mesh to obtain the $20-50 \mu \mathrm{m}$ particle size fraction (which was known from the previous study [21] to manifest very reproducible single-peak crystallization kinetics during linear heating). Amorphous character of the prepared $\mathrm{Se}_{70} \mathrm{Te}_{30}$ powder was verified by the Bruker AXS X-ray diffractometer D8 Advance equipped with a horizontal goniometer and scintillation counter utilizing $\mathrm{CuK}_{\alpha}$ radiation.

The DSC measurements were realized by using the Q200 (TA Instruments) heat-flow differential scanning calorimeter with implemented T-zero technology and equipped with RCS90 cooling accessory. The samples with masses in the range $6-7 \mathrm{mg}$ were hermetically sealed in aluminum pans; dry nitrogen at flow rate of $50 \mathrm{~cm}^{3} \cdot \mathrm{min}^{-1}$ was used as purge gas. Four series of heating scans was performed in the $20-200{ }^{\circ} \mathrm{C}$ range at selected heating rates $\left(q^{+}=3,5,7,10,20,30\right.$ and $\left.40{ }^{\circ} \mathrm{C} \cdot \mathrm{min}^{-1}\right)$. The first set of heating scans was done with the $\mathrm{Al}$ pans placed directly on the constantan platform within the DSC cell; in the other three cases a PTFE disc was placed in-between the platform and the Al crucible - discs with thicknesses $\mathrm{d}=0.080,0.152$ and $0.500 \mathrm{~mm}$ were used for the three measurements series. The PTFE discs and the Al pans with samples were always carefully positioned and centered of the DSC 
platform (the PTFE discs were used only at the sample position; no additional thermal resistance was used for the reference position, where only an empty $\mathrm{Al}$ pan was placed).

\section{Results}

The DSC crystallization data obtained for the $\mathrm{Se}_{70} \mathrm{Te}_{30} 20-50 \mu \mathrm{m}$ powder and the respective PTFE discs are shown in Fig. 1 - the series of measurements without any additional thermal resistance is denoted as " $\mathrm{d}=0 \mathrm{~mm}$ "; the physically meaningful tangential area-proportional baseline was used to isolate the pure crystallization signal and subtract the thermo-kinetic background. As is apparent, the signal significantly decreases and shifts to higher temperatures. Description of these kinetic changes can be done based on the standard kinetic equation [16]:

$$
d \alpha / d t=I \cdot A \cdot e^{-E / R T} \cdot f(\alpha)
$$

where $\alpha$ is the degree of conversion, $t$ is time, $T$ is temperature, $I$ is the integrated area under the kinetic peak, $A$ is the pre-exponential factor and $E$ is the apparent activation energy of the process. The kinetic model function $f(\alpha)$ is for the fine $\mathrm{Se}_{70} \mathrm{Te}_{30}$ powder known [21] to be best approximated by the nucleation-growth Johnson-Mehl-Avrami (JMA) equation [22 - 25]:

$$
f(\alpha)=n(1-\alpha)[-\ln (1-\alpha)]^{1-(1 / n)}
$$

where $n$ is the model kinetic exponent corresponding to the dimensionality of the process.

Starting with the model-free kinetics, the most pronounced effect of the additional thermal resistance is that of the markedly decreased apparent crystallization enthalpy - see Fig. 2A. In order to analyze the source of this deviation, the full thermo-kinetic equation [18] for DSCs and DTAs needs to be considered for the description of the heat flow in the system:

$$
\left(C_{r}-C_{s}\right) \cdot q^{+}-C_{s} \cdot d \Delta T / d t-\Delta H \cdot d \alpha / d t=\left(\frac{1}{R_{r}}-\frac{1}{R_{s}}\right) \cdot \Delta T
$$


where $R_{r}$ and $R_{s}$ are the systemic thermal resistances of the reference and sample sides, $C_{r}$ and $\mathrm{C}_{\mathrm{s}}$ are the systemic heat capacities of the reference and sample sides, and $\Delta \mathrm{T}$ is the difference of temperatures as given by the sensors thermocouples $\left(T_{s}-T_{r}\right)$. The presence of PTFE discs effectively increases both $C_{s}$ and $R_{s}$. Considering the PTFE heat capacity $c_{p}=1.0 \mathrm{~J} \cdot \mathrm{K}^{-1} \cdot \mathrm{g}^{-1}$ (compared to $\mathrm{c}_{\mathrm{p}}=0.9 \mathrm{~J} \cdot \mathrm{K}^{-1} \cdot \mathrm{g}^{-1}$ of aluminum) and heat conductivity $\lambda=0.25 \mathrm{~W} \cdot \mathrm{m}^{-1} \cdot \mathrm{K}^{-1}$ (compared to $\lambda=237 \mathrm{~W} \cdot \mathrm{m}^{-1} \cdot \mathrm{K}^{-1}$ of aluminum and $\lambda=0.026 \mathrm{~W} \cdot \mathrm{m}^{-1} \cdot \mathrm{K}^{-1}$ of air), the greatest contribution to the decrease of the measured heat flow signal is without question the large increase of $R_{s}$ due to the low PTFE conductivity. Based on the $\Delta H-d$ dependence shown in Fig. 1, the seemingly converging shape of the dependence suggests that a significant source of heat-dissipation-caused decrease of $\Delta \mathrm{H}$ can be associated also with the presence of the additional interface with non-ideal contact itself (platform-disc + disc-pan vs. originally only platform-pan), and in that regard the influence of the actual thickness of the PTFE disc decreases as d increases.

Similar situation arises for the thermal lag (temperature delay on the sensor) that is shown via the Kissinger [26] plot in Fig. 2B. This plot is used to determine the apparent activation energy $\mathrm{E}$ of the crystallization process by:

$$
\ln \left(\frac{q^{+}}{T_{p}^{2}}\right)=-\frac{E}{R T_{p}}+\text { const. }
$$

where $q^{+}$is heating rate, $R$ is the universal gas constant, $T_{p}$ is the temperature corresponding to the maximum of the DSC crystallization peak. As is apparent from Fig. 2B, the initial increase of $T_{p}$ with the addition of the PTFE disc with $d=0.076 \mathrm{~mm}$ is disproportionately larger (with respect to $d$ ) compared to the further $T_{p}$ increases for thicker PTFE discs - this effect can be observed for both low and high $\mathrm{q}^{+}$. This unambiguously indicates that the presence of the additional interface plays significant role for the hindrance of the heat transfer.

The increasing curvature of the dependences in Fig. 2B (with increasing d) results in a decrease of apparent activation energy E calculated according Eq. 4 (in the first 
approximation we have used simple linear fit of all depicted dependences instead of dealing with the illusory variable activation energy calculated from the derivation of the Fig. 2B data). Even more significant deviance of the $\mathrm{E}$ values is produced by the isoconversional methods determining $\mathrm{E}$ in dependence on $\alpha$. In Fig. 2B the activation energies averaged in the $\alpha$ range $0.3-0.7$ are shown for the differential Friedman [27] (Eq. 5) and integral Kissinger-AkahiraSunose KAS [28] (Eq. 6) methods:

$$
\begin{gathered}
\ln \left([d \alpha / d t]_{\alpha}\right)=-\frac{E}{R T_{\alpha}}+\text { const. } \\
\ln \left(\frac{q^{+}}{T_{\alpha}^{2}}\right)=-\frac{E}{R T_{\alpha}}+\text { const. }
\end{gathered}
$$

where $(\mathrm{d} \alpha / \mathrm{d} t)_{\alpha}, T_{\alpha}$ and $E_{\alpha}$ are the conversion rate, temperature and activation energy corresponding to arbitrarily chosen values of conversion $\alpha$. The progressively lower E values (with respect to increasing d) provided by the isoconversional methods (compared to the $\mathrm{T}_{\mathrm{p}^{-}}$ based Kissinger) confirm that the signal gets distorted more towards the high- $\alpha$ peak side.

The model-based kinetics was for the present data determined via the advanced analysis of the master-plot functions $z(\alpha)$ and $y(\alpha)[21]-$ see Eqs. 7 and 8:

$$
\begin{gathered}
z(\alpha)=\Phi \cdot T^{2} \\
y(\alpha)=\Phi \cdot e^{E / R T}
\end{gathered}
$$

Normalized master-plots for the borderline datasets $(\mathrm{d}=0 \mathrm{~mm}$ and $\mathrm{d}=0.500 \mathrm{~mm})$ are shown in Figs. 3A and 3B. Interestingly, the $z(\alpha)$ function seems to be quite robust with respect to thermal-lag-caused distortion of the DSC data; the $\mathrm{y}(\alpha)$ functions on the other hand show significant distortion due to the incorporation of $\mathrm{E}$. The averaged shift of the functions maxima with increasing $d$ is depicted in Fig. $3 \mathrm{C}$ together with $\alpha_{\max , z}=0.63$, which is the fingerprint for the JMA kinetics. Indeed, the JMA model stays valid for the description of even the largest added thermal resistance; i.e. the base asymmetry of the peak is changed only slightly. The manifestation of this slight change is however magnified for the formal 
calculation of the JMA exponent $n$, either directly from the $\mathrm{y}(\alpha)$ function maximum $\alpha_{\text {max,y }}$ (Eq. 9) [29] or from the double-logarithm linearization (Eq. 10) [16].

$$
\begin{gathered}
n=\frac{1}{1+\ln \left(1-\alpha_{\max , y}\right)} \\
\frac{d \ln [-\ln (1-\alpha)]}{d(1 / T)}=-\frac{n \cdot E}{R}
\end{gathered}
$$

Similarly to the difference between the $\mathrm{E}$ values determined by the $\mathrm{T}_{\mathrm{p}}$-based and isoconversional methods, also the determination of the JMA kinetic exponent $\mathrm{n}$ is strongly affected by the used methodology. Whereas the $\alpha_{\max , y}$ maximum based evaluation leads to only a minor change of $\mathrm{n}$ (from ca. 1.25 to 1.4 ), the double-logarithm linearization that averages the data from the whole DSC peak is affected by the added thermal resistance significantly more, leading to $\mathrm{n}$ changing from ca. 1.3 to 1.7 . Both effects are still relatively small but only because the fine $\mathrm{Se}_{70} \mathrm{Te}_{30}$ powder crystallizes strictly from the surface, leading to the $\mathrm{n}$ values in-between 1.0 and 1.5. Similar level of distortion would in case of a material with the initial asymmetry corresponding to e.g. two-dimensional growth $(n=2)$ lead to a shift to the values of $\mathrm{n}$ higher than 3 (indicating growth of 3D crystallites), significantly changing the potential interpretation of the data.

\section{Discussion}

In the previous section the results of kinetic analysis for the fine $\mathrm{Se}_{70} \mathrm{Te}_{30}$ powder crystallization being affected by added thermal resistance in the form of the PTFE discs of different thicknesses. To further explore the consequences of the increased thermal resistance on the shape of the kinetic curve, we have utilized the flexible empiric autocatalytic AC model (Eq. 11) [16] to describe the simultaneous influence of $\mathrm{d}$ and $\mathrm{q}^{+}$on the DSC peak asymmetry: 


$$
f(\alpha)=\alpha^{M}(1-\alpha)^{N}
$$

where $\mathrm{M}$ and $\mathrm{N}$ are the $\mathrm{AC}$ kinetic exponents reflecting the peak shape. The obtained trends are for the two borderline PTFE thicknesses $(\mathrm{d}=0 \mathrm{~mm}$ and $\mathrm{d}=0.500 \mathrm{~mm})$ shown in Figs. 4A and $4 \mathrm{~B}$. The general effect of the added resistance can be expressed by the increasing $\mathrm{M} / \mathrm{N}$ ratio: $0.20 \pm 0.02$ for $\mathrm{d}=0 \mathrm{~mm}$, and $0.31 \pm 0.02$ for $\mathrm{d}=0.500 \mathrm{~mm}$.

Since the ultimate goal of the kinetic analysis is the possibility to make kinetic predictions, we have explored the influence of the added thermal resistance on both the interpolated and extrapolated predictions. In Fig. 4C the interpolated predictions simulated for $\mathrm{q}^{+}=10^{\circ} \mathrm{C} \cdot \mathrm{min}^{-1}$, AC model, and the borderline sets of experimental conditions (PTFE thicknesses 0 and $0.5 \mathrm{~mm}$, and kinetic exponents determined from the data obtained at 3 and $\left.40^{\circ} \mathrm{C} \cdot \mathrm{min}^{-1}\right)$ - complete sets of kinetic parameters for the simulations are listed in Table 1 . The heating rate of $10^{\circ} \mathrm{C} \cdot \mathrm{min}^{-1}$ was deliberately chosen to place the simulated data in the middle of the experimentally measured $\mathrm{q}^{+}$range. Yet, there is a significant shift in temperature and asymmetry of the data simulated for the presence of thermal resistance. Even larger consequences occur when extrapolating the kinetic prediction outside of the measured temperature range. This is demonstrated in Fig. 4D, where the results for isothermal annealing at $80{ }^{\circ} \mathrm{C}$ are shown for the same four sets of parameters as in Fig. 4C. Despite the extrapolation being small (close to the original measurements, $\Delta \mathrm{T}_{\text {pred }} \approx 10-15^{\circ} \mathrm{C}$ ), the effect of thermal resistance is already comparable with that of $\mathrm{q}^{+}$, resulting in errors of several tenths of $\%$. Note that with larger extrapolations to lower temperatures the deviations would magnify exponentially according to the differences in E. For example, in case of annealing at $50{ }^{\circ} \mathrm{C}$ the times needed for reaching $\alpha=0.999$ would be 67 days $\left(\mathrm{d}=0 \mathrm{~mm}, \mathrm{q}^{+}=3{ }^{\circ} \mathrm{C} \cdot \mathrm{min}^{-1}\right), 17$ days $\left(\mathrm{d}=0 \mathrm{~mm}, \mathrm{q}^{+}=40^{\circ} \mathrm{C} \cdot \mathrm{min}^{-1}\right), 20$ days $\left(\mathrm{d}=0.5 \mathrm{~mm}, \mathrm{q}^{+}=3^{\circ} \mathrm{C} \cdot \mathrm{min}^{-1}\right)$ and 6 days $(\mathrm{d}=0.5 \mathrm{~mm}$, $\left.\mathrm{q}^{+}=40^{\circ} \mathrm{C} \cdot \mathrm{min}^{-1}\right)-$ see the Supplemental online material for the full predictions at this temperature. This not only demonstrates the influence of $d$ on the isothermal predictions 
(d $\alpha \cdot \mathrm{dt}^{-1}$ increasing with $\Delta \mathrm{T}_{\text {pred }}$ due to the decreasing apparent $\mathrm{E}$, which is a general consequence of larger temperature lags at higher $\mathrm{q}^{+}$) but also the utmost importance of the predictions being made based on the correct set of the kinetic calculations. In case of the lowtemperature predictions the most relevant experimental measurements are those performed at low $\mathrm{q}^{+}[30,31]$, which are often missing in literature; it is also important to bear in mind that E is by far the most crucial parameter in this regard, i.e. although the DSC data obtained at lower $\mathrm{q}^{+}$are usually of insufficient quality for high- $\mathrm{r}^{2}$ description, they are still valuable for calculation of E.

As was already mentioned in section 3, the increased thermal resistance $R_{s}$ (see Eq. 3) is the one of the main sources of thermal lag on the sample side. If we plot the time lag "constant" calculated as:

$$
t_{\text {lag }}=\left(T_{p}^{d}-T_{p}^{0}\right) / q^{+}
$$

(where $\mathrm{T}_{\mathrm{p}}{ }^{\mathrm{d}}$ and $\mathrm{T}_{\mathrm{p}}{ }^{0}$ are maxima of the kinetic peaks for the for the given $\mathrm{q}^{+}$and $\mathrm{d}$, or $\mathrm{q}^{+}$and $d=0$, respectively) against $\mathrm{q}^{+}$, then the resulting values (see Fig. 5A) clearly increase with $d$ ( $\mathrm{t}_{\text {lag }}$ independent from $\mathrm{d}$ would suggest the additional interface being the vastly dominant source for thermal resistance) but they are clearly not constant either and decrease with $\mathrm{q}^{+}$, which suggests the real heat transfers being more complicated than introduced by Eq. 3. In fact, for the cutting edge fast scanning calorimeters (FSC) the thermal lag is modeled according to Eq. 13a [32], where the first left-hand-side term accounts for the interface + dissipation, the second term describes the conduction of heat within the sensor (due to the specific FSC sensor geometry) and the third term accounts for the actual thermal resistance within the sensor-sample heat path; $\mathrm{a}_{1}$ to $\mathrm{a}_{5}$ are constants, and $\mathrm{P}$ is the property proportionate to the main source of thermal resistance (mass, or in the present case d).

$$
T_{p}^{d}-T_{p}^{0}=a_{1}+a_{2} \cdot q^{+a 3}+a_{4} \cdot q^{+} \cdot P^{a 5}
$$


If we attempt to model the present $\Delta \mathrm{T}$ data according Eq. $13 \mathrm{a}$ (with $\mathrm{q}^{+}$in ${ }^{\circ} \mathrm{C} \cdot \mathrm{min}^{-1}$ ), the description is of relatively low quality (see Fig. 5B), with the sum of squared residui RSC = 3.194 and coefficients shown in Eq. 13b. Note the coefficients $a_{1}=0$ and $a_{5}=1$ (the latter is in agreement with the assumptions listed in [32]). Nevertheless, the interpretation of the coefficients cannot be reliably done with the core description being inaccurate. As is apparent from Fig. 5B, main deviations arise from the data at 30 and $40{ }^{\circ} \mathrm{C} \cdot \mathrm{min}^{-1}$, which also show high scatter. When omitting these datapoints from all three d dependences, accuracy of the fit dramatically increases $(\mathrm{RSC}=0.458$, see Fig. $5 \mathrm{C}$ ) and the description follows Eq. 13c.

$$
\begin{gathered}
T_{p}^{d}-T_{p}^{0}=0.396 \cdot q^{+0.370}+0.361 \cdot q^{+} \cdot d^{1.033} \\
T_{p}^{d}-T_{p}^{0}=0.363+0.467 \cdot q^{+} \cdot d^{0.812}
\end{gathered}
$$

The coefficients in Eq. 13c already very well correspond to the general conception of the heat transfer associated with the addition of the PTFE thermal resistance - first right-side term represents the invariant contribution from the additional interface, the term No. 2 from Eq. 13a is missing entirely (the non-linear optimization resulted in the coefficient $a_{3}=0$ ), the second right-side term in Eq. $13 \mathrm{c}$ represents the heat conduction through the PTFE disc. Note the coefficient $a_{5}=0.81$ indicating a sub-linear dependence of thermal resistance on the sample mass/thickness - this appears to be the consequence of the decreasing influence of heat losses due to radiation from the PTFE discs side areas not being in the direct path of the heat transfer between the $\mathrm{Al}$ pan and the DSC platform.

\section{Conclusions}

The consequences of added thermal resistance (in the form of PTFE discs inserted inbetween the DSC sensor platform and Al pan with sample) on the crystallization kinetics of powdered $\mathrm{Se}_{70} \mathrm{Te}_{30}$ glass were demonstrated. With increasing disc thickness from 0 to $0.5 \mathrm{~mm}$ the crystallization enthalpy decreased by $36 \%$, the decrease decelerates significantly after 
reaching $\mathrm{d} \approx 0.2 \mathrm{~mm}$. For the same conditions the activation energies determined by the Kissinger, KAS and Friedman methods decreased by 24, 26 and $32 \%$, respectively, with the deceleration being weaker as the full DSC curve data are being integrated into the calculation $\left(\mathrm{T}_{\mathrm{p}}\right.$-based method $>$ integral isoconversional method $>$ differential isoconversional method). The main source for the decreasing values of $\mathrm{E}$ was the progressively increased curvature at high $\mathrm{q}^{+}$. The addition of thermal resistance had only minor influence on the peak asymmetry that became more significant only at highest $\mathrm{q}^{+}$; i.e. the model-based kinetic analysis was distorted only weakly.

Regarding the kinetic predictions, the interpolated ones were basically not affected by the added thermal resistance. The extrapolated kinetic predictions suffered from already significant distortions (as a consequence of changing E values), that exponentially increased with the extrapolation range, causing deviations in the predicted degree of conversion similar in their magnitude to the influence of applied heating rate. The temperature shift caused by added thermal lag was found to be for the low-to-moderate heating rates well modeled as $\Delta \mathrm{T}=\mathrm{I}+\mathrm{K} \cdot \mathrm{q}^{+} \cdot \mathrm{m}^{\mathrm{k}}$, where $\mathrm{I}$ is the constant associated with the thermal resistance of the added interface, $\mathrm{K}$ and $\mathrm{k}$ are constants, and $\mathrm{m}$ is the quantity proportionate to the mass of the body causing the additional thermal resistance.

\section{Acknowledgments}

This work has been supported by the Czech Science Foundation under project No. 1711753 S.

\section{References}

[1] S. Vyazovkin, A.K. Burnham, J.M. Criado, L.A. Pérez-Maqueda, C. Popescu, N. Sbirrazzuoli, ICTAC Kinetics Committee recommendations for performing kinetic computations on thermal analysis data, Thermochim Acta. 520 (2011) 1-19

[2] S. Vyazovkin, K. Chrissafis, M.L. Di Lorenzo, N. Koga, M. Pijolat, B. Roduit, N. Sbirrazzuoli, J.J. Sunol. ICTAC Kinetics Committee recommendations for collecting 
experimental thermal analysis data for kinetic computations. Thermochim Acta. 590 (2014) 1-23

[3] L. Nowicki, D. Siuta, M. Godala. Determination of the chemical reaction kinetics using isothermal reaction calorimetry supported by measurements of the gas production rate: A case study on the decomposition of formic acid in the heterogeneous Fenton reaction. Thermochimica Acta 653 (2017) 62-70.

[4] N.V. Muravyev, A.N. Pivkina. New concept of thermokinetic analysis with artificial neural networks. Thermochimica Acta 637 (2016) 69-73.

[5] M. Catauro, A. Dell'Era, S.V. Ciprioti. Synthesis, structural, spectroscopic and thermoanalytical study of sol-gel derived $\mathrm{SiO} 2-\mathrm{CaO}-\mathrm{P} 2 \mathrm{O} 5$ gel and ceramic materials. Thermochimica Acta 625 (2016) 20-27.

[6] S. Zeman, Q.L. Yan, M. Gozin, F.Q. Zhao, Z. Akstein. Thermal behavior of 1,3,5trinitroso-1,3,5-triazinane and its melt-castable mixtures with cyclic nitramines. Therochimica Acta 615 (2015) 51-60.

[7] M. Khachani, A. El Hamidi, M. Kacimi, M. Halim, S. Arsalane. Kinetic approach of multi-step thermal decomposition processes of iron(III) phosphate dihydrate FePO4 center dot 2H(2)O. Thermochimica Acta 610 (2015) 29-36.

[8] E.J. Grajales, E.A. Alacron, A.L. Villa. Kinetics of depolymerization of paraformaldehyde obtained by thermogravimetric analysis. Thermochim. Acta 609 (2015) 49-60.

[9] N.N. Begovic, N.N. Stojanovic, S.B. Ostojic, A.M. Radulovic, V.A. Blagojevic, B. Simonovic, D.M. Minic. Thermally induced polymerization of binuclear [Ni$2(\mathrm{en})(2)(\mathrm{H} 2 \mathrm{O})(6)(\mathrm{pyr})]$ center dot 4H(2)O complex. Thermochim. Acta 607 (2015) 8291.

[10] R. Font. Potential kinetic model for thermal decomposition of complex organic compounds: Significance of parameters and engineering application. Thermochimica Acta 591 (2014) 81-95.

[11] R. Svoboda. Crystallization kinetics in Se-Te glassy system - effect of long-term material degradation. Thermochim. Acta 639 (2016) 108-119

[12] R. Svoboda. Oxidation-accelerated crystallization of $\left(\mathrm{GeS}_{2}\right)_{\mathrm{y}}\left(\mathrm{Sb}_{2} \mathrm{~S}_{3}\right)_{1-\mathrm{y}}$ chalcogenide glasses. J. Non-Cryst. Sol. 456 (2017) 88-94

[13] R. Svoboda. Tangential area-proportional baseline interpolation for complex-process DSC data - yes or no? Thermochim. Acta 658 (2017) 55-62

[14] R. Svoboda. Importance of proper baseline identification for the subsequent kinetic analysis of derivative kinetic data, part 2. J. Therm. Anal. Calorim. 131 (2018) 18891897.

[15] R. Svoboda. Reaction/crystallization kinetics studied via in-situ XRD: experimental conditions versus methods of kinetic analysis. Phil. Mag. - submitted.

[16] J. Šesták. Thermophysical Properties of Solids, Their Measurements and Theoretical Analysis. Elsevier: Amsterdam; 1984.

[17] R. Svoboda, J. Málek. Description of macroscopic relaxation dynamics in glasses. J. Non-Cryst. Solids 378 (2013) 186-195

[18] P. Holba, J. Šesták. Heat inertia and its role in thermal analysis. J. Therm. Anal. Calorim. 121 (2015) 303-307.

[19] R. Svoboda, P. Pustková, J. Málek. Volume relaxation of a-Se studied by mercury dilatometry. J. Non-Cryst. Solids 352 (2006) 4793-4799

[20] J. Orava, A.L. Greer, B. Gholipour, D.W. Hewak, C.E. Smith. Characterization of supercooled liquid $\mathrm{Ge}_{2} \mathrm{Sb}_{2} \mathrm{Te}_{5}$ and its crystallization by ultrafast-heating calorimetry. Nat. Mater. 11 (2012) 249-283. 
[21] R. Svoboda, J. Málek. Interpretation of crystallization kinetics results provided by DSC. Thermochimica Acta 526 (2011) 237-251

[22] W.A. Johnson, K.F. Mehl. Reaction kinetics in processes of nucleation and growth. Trans. Am. Inst. Min. (Metall) Eng. 135 (1939) 416-42.

[23] M. Avrami. Kinetics of phase change I-general theory. J. Chem. Phys. 7 (1939) 110312.

[24] M. Avrami. Kinetics of phase change. II-transformation-time relations for random distribution of nuclei. J. Chem. Phys. 7 (1940) 212-24.

[25] M. Avrami. Granulation, phase change, and microstructure - kinetics of phase change III. J. Chem. Phys. 7 (1941) 177-84.

[26] H.E. Kissinger, Reaction kinetics in differential thermal analysis, Anal.Chem. 29 (1957) 1702-1706.

[27] H.L. Friedman, Kinetics of thermal degradation of char-forming plastics from thermogravimetry. Application to a phenolic plastic, J. Polym. Sci., Part C 6 (1964) 183-195

[28] T. Akahira, T. Sunose, Method of determining activation deterioration constant of electrical insulating materials, Res. Report Chiba Inst. Technol. (Sci. Technol.) 16 (1971) 22-31

[29] J. Malek, The kinetic-analysis of nonisothermal data, Thermochim. Acta 200 (1992) 257-269.

[30] D. Brandová, R. Svoboda, Z. Olmrová Zmrhalová, J. Chovanec, R. Bulánek. Crystallization kinetics of glassy materials: the ultimate complexity? J. Therm. Anal. Calorim. 134 (2018) 825-834

[31] J. Romanová, R. Svoboda, I. Obadalová, L. Beneš, T. Pekárek, L. Krejčík, A. Komersová. Amorphous Enzalutamide - non-isothermal recrystallization kinetics and thermal stability. Thermochim. Acta 655 (2018) 134-141

[32] S. van Herwaarden, E. Iervolino, F. van Herwaarden, T. Wijffels, A. Leenaers, V. Mathot. Design, performance and analysis of thermal lag of the UFS1 twincalorimeter chip for fast scanning calorimetry using the Mettler-Toledo Flash DSC 1. Thermochim. Acta 522 (2011) 46-52.

\section{Table 1}

Sets of kinetic parameters determined via single-curve model-based analysis and derivative tangent model-free calculation for the combinations of borderline conditions: $\mathrm{q}^{+}=3$ and $40^{\circ} \mathrm{C} \cdot \mathrm{min}^{-1}, \mathrm{~d}=0$ and $0.5 \mathrm{~mm}$.

\begin{tabular}{|l|l|l|l|l|}
\hline $\mathrm{q}^{+} /{ }^{\circ} \mathrm{C} \cdot \mathrm{min}^{-1}$ & 3 & 3 & 40 & 40 \\
\hline $\mathrm{d} / \mathrm{mm}$ & 0 & 0.5 & 0 & 0.5 \\
\hline $\mathrm{E} / \mathrm{kJ} \cdot \mathrm{mol}^{-1}$ & 151.9 & 131.9 & 124.9 & 96.7 \\
\hline $\log \left(\mathrm{A} / \mathrm{s}^{-1}\right)$ & 18.69 & 15.90 & 15.11 & 11.29 \\
\hline $\mathrm{M}_{\mathrm{AC}}$ & 0.256 & 0.343 & 0.391 & 0.570 \\
\hline $\mathrm{N}_{\mathrm{AC}}$ & 1.019 & 0.958 & 1.139 & 1.293 \\
\hline
\end{tabular}




\section{Figure captions}

Fig. 1: Sets of DSC crystallization peaks obtained at different heating rates. Each graph corresponds to a situation with different PTFE disc of a particular thickness d used; $\mathrm{d}=0.000 \mathrm{~mm}$ indicates usage of no PTFE disc. Exothermic effects evolve in the upwards direction.

Fig. 2: A) Apparent crystallization enthalpy (averaged over all applied $\mathrm{q}^{+}$) plotted in dependence on the thickness of the used PTFE disc.

B) Kissinger plots for the determination of E; each dependence corresponds to a PTFE disc with different thickness being used.

C) Apparent activation energies (determined by the Kissinger, KAS and Friedman methods) plotted in dependence on the thickness of the used PTFE disc.

Fig. 3: A) Master-plot functions $z(\alpha)$ determined for the crystallization measurements obtained at different $\mathrm{q}^{+}$and two borderline PTFE disc thicknesses - black datapoints correspond to $\mathrm{d}=0 \mathrm{~mm}$, red datapoints correspond to $\mathrm{d}=0.5 \mathrm{~mm}$.

B) Masterplot functions $y(\alpha)$ determined for the crystallization measurements obtained at different $\mathrm{q}^{+}$and two borderline PTFE disc thicknesses - black datapoints correspond to $\mathrm{d}=0 \mathrm{~mm}$, red datapoints correspond to $\mathrm{d}=0.5 \mathrm{~mm}$.

C) Maxima of the masterplot functions $z(\alpha)$ and $y(\alpha)$ plotted in dependence on the thickness of the used PTFE disc. The red dashed line corresponds to $z(\alpha)=0.632$, which is a fingerprint of the JMA model.

D) JMA kinetic exponents (determined from the $\alpha_{\max , \mathrm{y}}$ and double logarithm function) plotted in dependence on the thickness of the used PTFE disc.

Fig. 4: A) Kinetic exponent $M$ of the $\mathrm{AC}$ model determined for the crystallization measurements obtained at different $\mathrm{q}^{+}$and two borderline PTFE disc thicknesses black datapoints correspond to $\mathrm{d}=0 \mathrm{~mm}$, red datapoints correspond to $\mathrm{d}=0.5 \mathrm{~mm}$.

B) Kinetic exponent $\mathrm{N}$ of the $\mathrm{AC}$ model determined for the crystallization measurements obtained at different $\mathrm{q}^{+}$and two borderline PTFE disc thicknesses black datapoints correspond to $\mathrm{d}=0 \mathrm{~mm}$, red datapoints correspond to $\mathrm{d}=0.5 \mathrm{~mm}$.

C) Kinetic predictions for non-isothermal heating step at $\mathrm{q}^{+}=10^{\circ} \mathrm{C} \cdot \mathrm{min}^{-1}$. Each curve corresponds to one set of kinetic parameters listed in Table 1.

D) Kinetic predictions for isothermal annealing step at $\mathrm{T}=80{ }^{\circ} \mathrm{C}$. Each curve corresponds to one set of kinetic parameters listed in Table 1.

Fig. 5: A) Time lag associated with the added thermal resistance calculated from the data shown in Fig. 2B according Eq. 12.

B) Temperature lag associated with the added thermal resistance calculated from the data shown in Fig. 2B. The data are fit using Eq. 13a - the result of the non-linear optimization represents Eq. $13 \mathrm{~b}$.

C) Temperature lag associated with the added thermal resistance calculated from the data shown in Fig. 2B. The data are fit using Eq. 13a (high-q ${ }^{+}$red-based points were omitted from the fit) - the result of the non-linear optimization represents Eq. 13c. 
Fig1
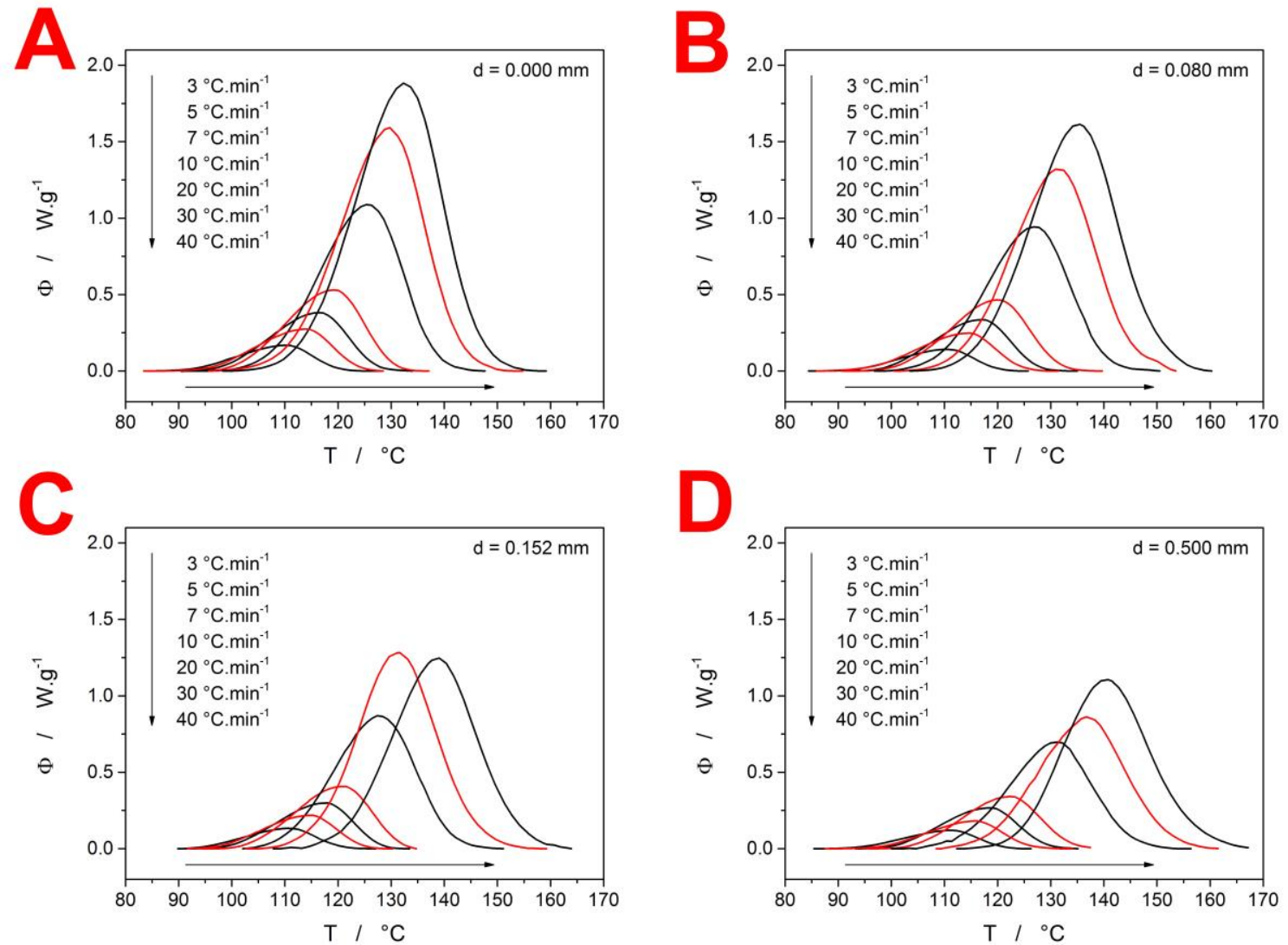
Fig 2
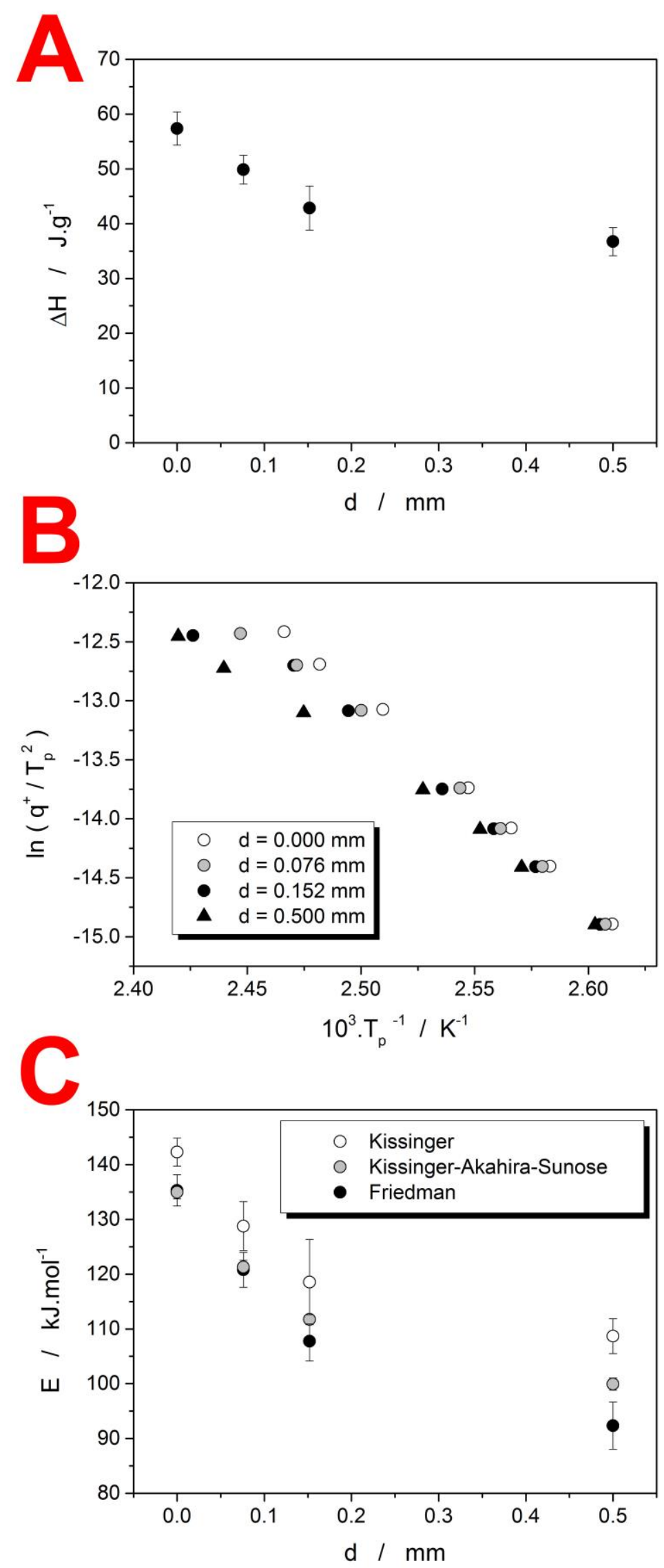
Fig 3
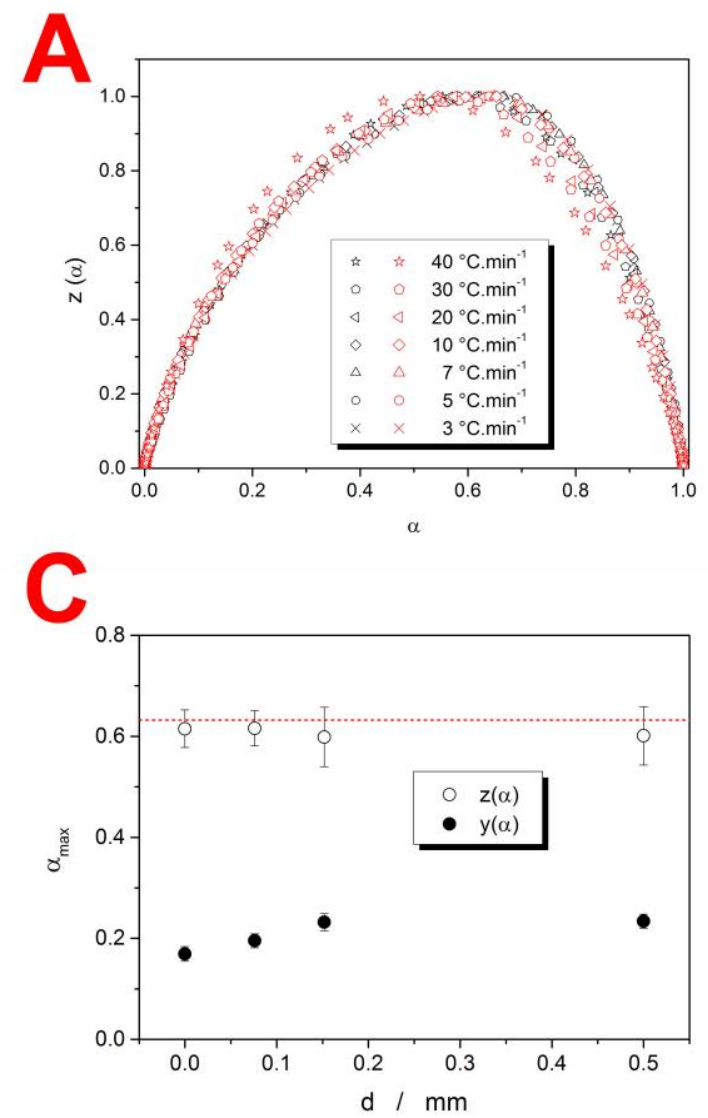

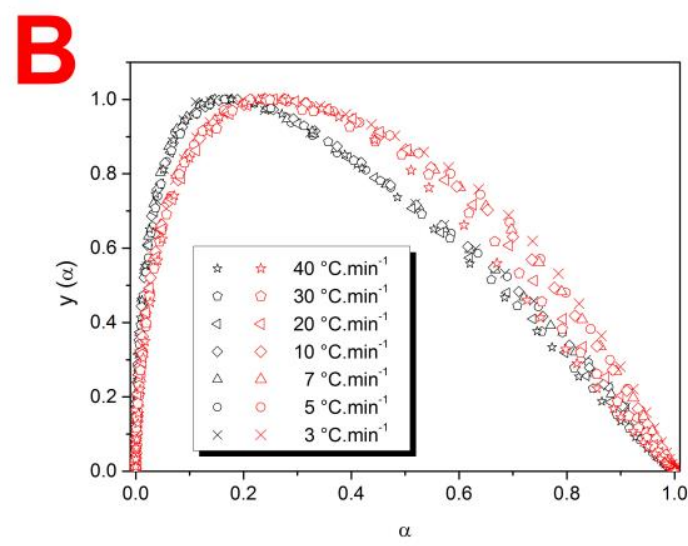

D

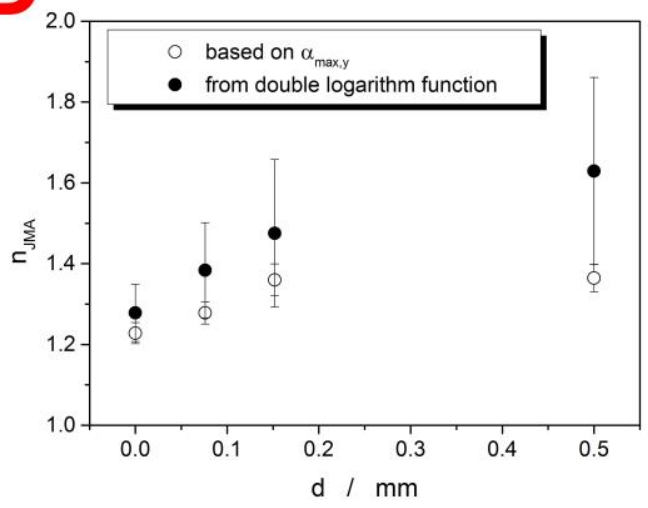


Fig 4
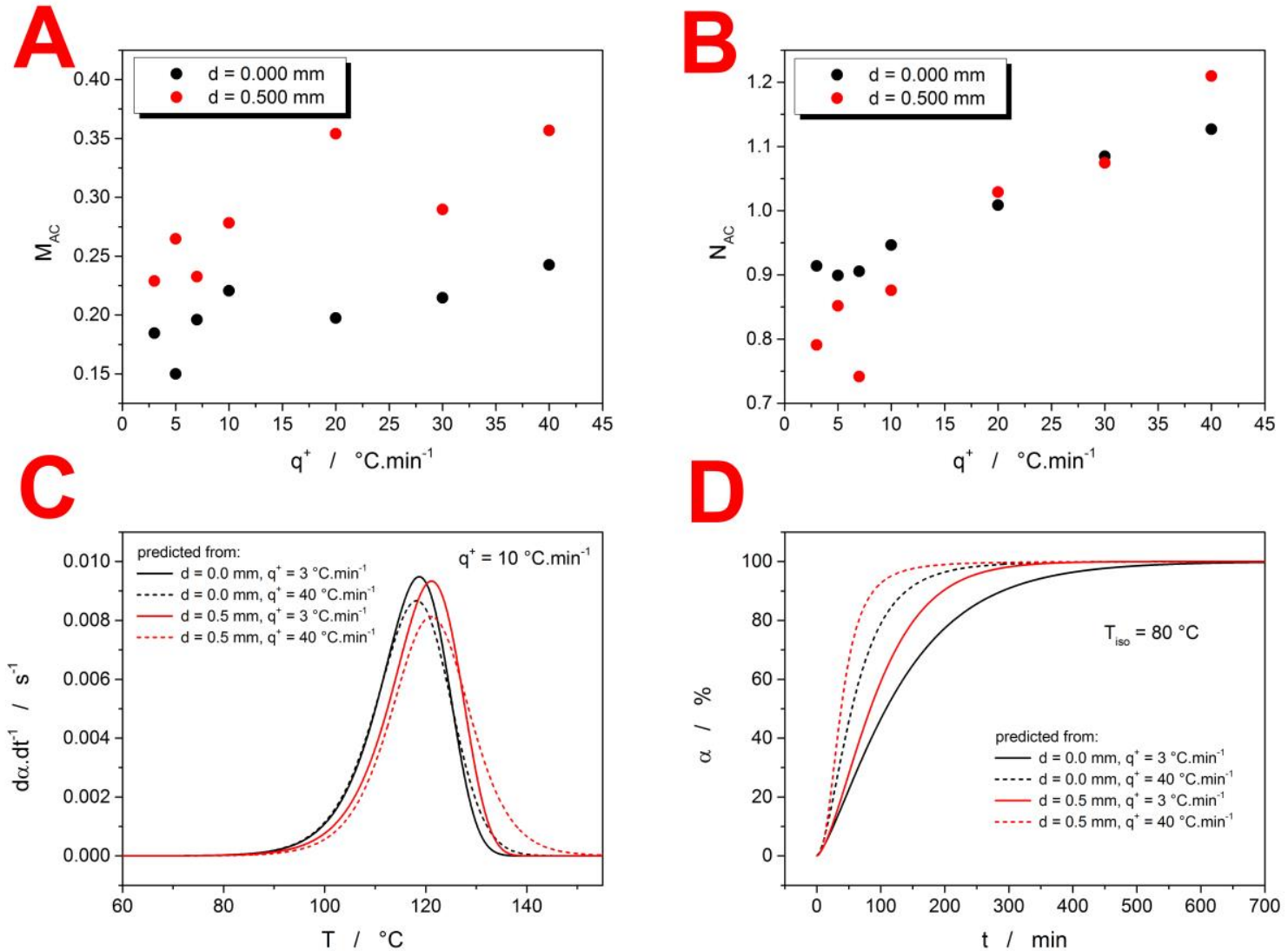
Fig 5

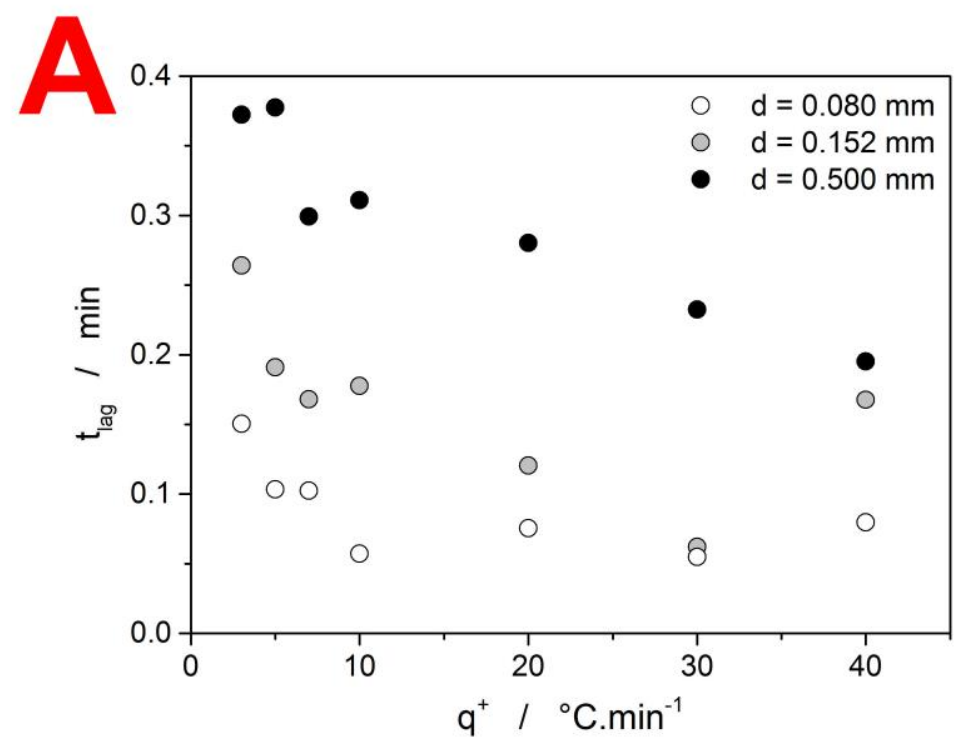

B
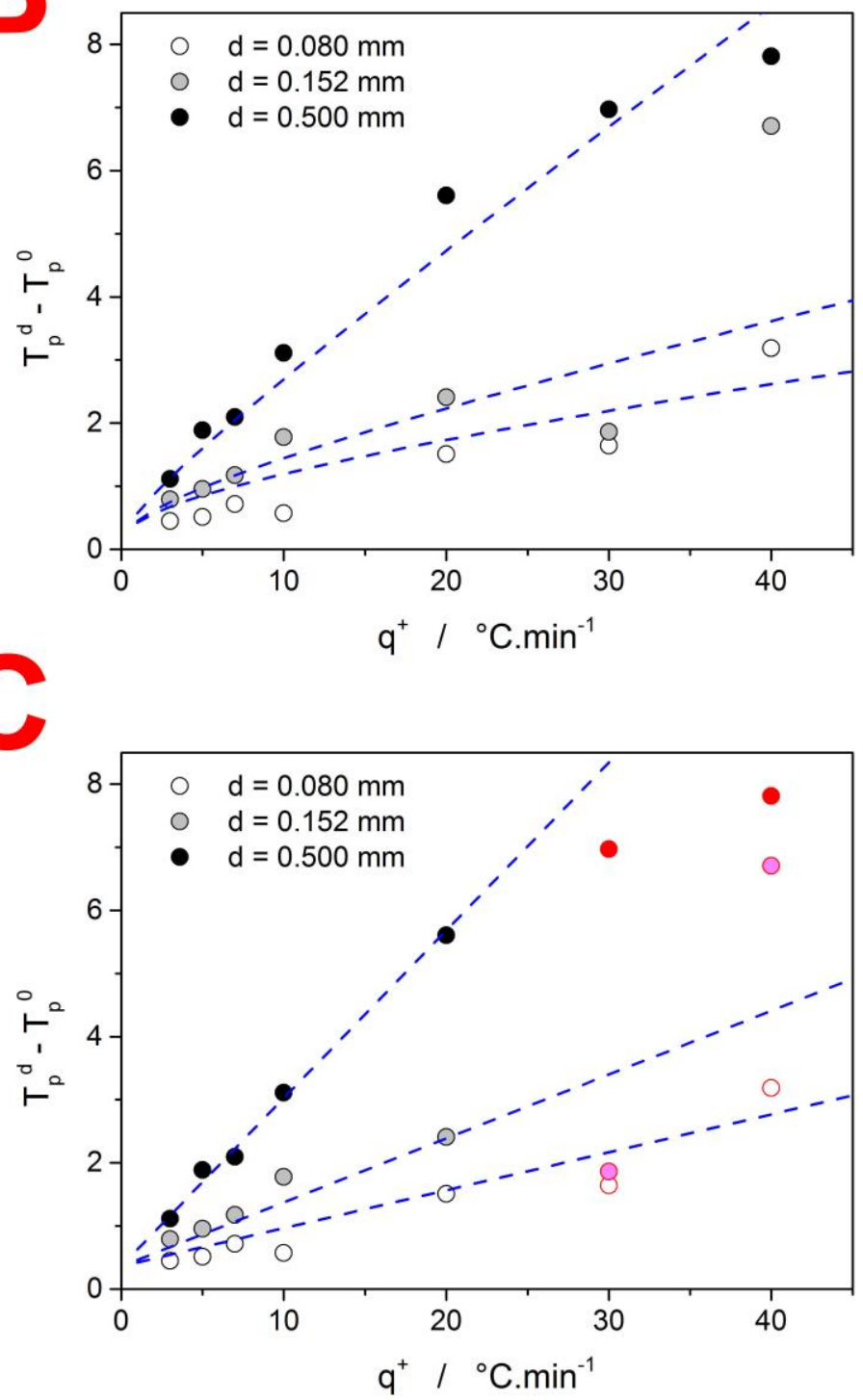